\title{
Maternal reporting of behaviour following very severe blunt head injury
}

\author{
Glynda Kinsella, Sue Packer, John Olver
}

\begin{abstract}
Mothers of $\mathbf{4 0}$ very severely head injured male subjects rated their son's behaviour on the Current Behaviour Scale and their ratings were compared with mothers' ratings of 40 control male subjects. The scale was able to discriminate the two groups, by utilising two factors-loss of emotional control and loss of motivation. The mothers' level of emotional distress was closely related to their reporting of loss of emotional control in their sons, but reporting of loss of motivation, or lowered arousal, was strongly predicted by the functional disability of the son. The utility of refining the measurement of post-trauma behaviour is discussed.
\end{abstract}

Closed head injury produces alterations in behaviour and personality style. These changes are commonly cited as the most disruptive consequences following head injury in relation to family cohesion, long term social adjustment and re-integration into the community. ${ }^{1-4}$

Behaviour after head injury has been traditionally difficult to quantify especially as the individual's pre-existing personality characteristics and response to trauma will interact with the neuropathologically mediated changes in behaviour. ${ }^{5}$ Few scales have been developed to capture the specific nature of the behavioural profile head injury. Levin et $a l^{6}$ have developed a neurobehavioural rating scale to assess the behavioural sequelae following head injury but it is targetted for completion by trained professionals using direct observation in rehabilitation programmes. Unfortunately, in the long term, very few head injured individuals attend such facilities and it is commonly the family who are attempting to cope with the ensuing behavioural issues. A scale for describing their perceptions of the quality of the behavioural change post-trauma is still needed.

Clinically there are common groups of behavioural change that have been frequently noted. Two important groups of behaviours are those relating to loss of emotional control, and those relating to lowered arousal or lack of motivation. These are considered to represent complex manifestations of underlying brain pathology, commonly involving frontal lobe functioning. Brooks and McKinlay ${ }^{4}$ present data from a follow up study of 55 severely head injured subjects and their close relatives and report that as the severity of injury increases the relatives are more likely to report an overall behavioural change in the injured patient. Interestingly, a pattern of relationship could not be discerned between the severity of the injury and dysfunction on individual behavioural items, merely that increasing diffuse damage promoted the likelihood of complex behavioural dysfunction.

The literature highlights that the disruptive behaviour patterns of the head injured are related to stress experienced by the family. ${ }^{78}$ As yet, however, there is a lack of analysis of the specific components of the behaviour patterns that differentially contribute to the experienced stress of the family. It could also be hypothesised that different members of the close family will experience different stressors that is, the issues for the spouse in the marital relationship will not mirror those for the parent of a severely head injured individual.

Our study chose to focus on the relationship between the severely head injured male population and their mothers since the prototypical head injured subject will be a young male, returning to live at home in the care of his ageing parents. ${ }^{9}$ Preliminary work by our research group ${ }^{10}$ suggested a relationship between specific aspects of the behavioural profile of the head injured and the psychiatric health of the mother. Our aim in this study was to extend this pilot work.

The first aim of this study was to develop the methodology to quantify the behavioural profile of the head injured, and specifically to describe the behaviours of loss of emotional control and loss of motivation, or lowered arousal, as perceived by the mothers of those with head injuries. We then determined the variables that were related to the mother's reporting of behavioural outcome in those with head injuries. We needed to know whether specific groups of behaviours were particularly stressful for the mother and would be predictive of her psychiatric status. Additionally, the relationship if any, between the severity and chronicity of the brain injury with the behavioural profile of those with head injuries was to be addressed.

\section{Method}

Subjects

Forty head injured male subjects and their mothers were studied. All the $\mathbf{4 0}$ subjects had sustained a very severe closed head injury and were selected from past records of a number of 
Table 1 Distribution of length of coma and period of post-traumatic amnesia (PTA) in the head injured subjects $(n=40)$

\begin{tabular}{llc}
\hline Days & PTA $n(\%)$ & COMAn(\%) \\
\hline Less than 1 & 0 & $5(12 \%)$ \\
$1-6$ & 0 & $8(20 \%)$ \\
$7-14$ & $10(25 \%)$ & $9(23 \%)$ \\
$15-28$ & $10(25 \%)$ & $7(18 \%)$ \\
More than 28 & $20(50 \%)$ & $11(27 \%)$ \\
\hline
\end{tabular}

rehabilitation hospitals in Melbourne. Head injury was defined as "blunt injury" to the head resulting in significant loss of consciousness and a period of post-traumatic amnesia (PTA) of at least seven days (table 1). Subjects with depressed skull fractures were included but subjects with focal penetrating wounds were excluded. Potential subjects were only investigated if they were aged between 16 and 35 years of age at the time of interview. This parameter was introduced to reduce the heterogeneity in a relatively small sample size. The mean age of the eventual subject group was 27 years (range 17-35 years). The subjects were at least 24 months post-injury (range two-15 years) and $68 \%$ were five years or longer post-injury. In other words the sample represented a chronic group of survivors of very severe head injury. The most common causes of the injury were road traffic accidents $(75 \%)$ and falls $(18 \%)$.

The selection of a control group for a head injury study is always problematical (see McKinlay and Brooks ${ }^{11}$ ) and in this study it was particularly difficult because of the chronicity and retrospective sampling of the subjects. It was eventually decided to select a community control group, matched on age, sex, and years of education. This was estimated to control for those features of the subjects most immediately pertinent to the research questions. A premorbid behavioural profile was not sought from the respondents as it was anticipated that the chronicity of the group would create unreliability in these reports. Forty community controls were selected from friends and acquaintances of the head injured subjects, and acquaintances and networks available to the researchers. The groups were similar for sex, age, and years of education (table 2).

Head injured and control subjects were only included in the study if they either lived with their mother or had regular and frequent contact with her. Mothers of head injured subjects had a mean age of 55 years (range: $36-$ 69 years), while the mean age of control subjects' mothers was 50 years (range: 30-65 years).

\section{Behavioural profile of the head injured}

To quantify the behaviour of the head injured the Current Behaviour Scale ${ }^{12}$ was used. This

Table 2 Means (SD) for age and education of mothers and sons from the head injured and control samples

\begin{tabular}{llllll}
\hline & \multicolumn{2}{l}{$\begin{array}{l}\text { Head injured group } \\
(n=40)\end{array}$} & & \multicolumn{2}{l}{$\begin{array}{l}\text { Control group } \\
(n=40)\end{array}$} \\
\cline { 2 - 3 } \cline { 5 - 6 } & Mothers & Sons & & Mothers & Sons \\
\hline Age (years) & $55(7 \cdot 5)$ & $27(4 \cdot 4)$ & & $50(7 \cdot 1)$ & $24(5 \cdot 3)$ \\
Education (years) & $10(1 \cdot 4)$ & $12(2 \cdot 1)$ & & $10(1 \cdot 9)$ & $13(2 \cdot 7)$ \\
\hline
\end{tabular}

scale was developed building on the preliminary work reported by Elsass and Kinsella. ${ }^{13}$ The measurement technique used in the scale was the Semantic Differential. ${ }^{14}$ In its general form the Semantic Differential consists of a set of bi-polar adjective scales on which the subject is required to rate a stimulus or concept. In this behaviour scale, for each item, the mother indicated the direction of association of her perception of her son's behaviour with the concept. It was completed by the mother in relation to her son's behaviour over the previous few weeks and the intensity of association was rated on a seven point scale. The 25 items, or adjective scales, were based on the most common behaviours following severe head injury as reported in the literature, for example, quick tempered-even tempered, alert-drowsy, irritable —easy going. A score of seven on any individual item indicated "head injury" behaviour.

Severity of brain injury and current functional disability.

Since the construction of the population was essentially retrospective in terms of identifying the head injured subjects from previous medical records, the documentation of the exact length of PTA was frequently considered to be unreliable. However, converging data from the mother's reports and medical records suggested high levels of accuracy in the estimation of the length of coma. For these reasons it was decided to use the length of coma but not the length of PTA as an estimate of severity of brain injury and to supplement this variable by establishing a current level of functional disability, or functional severity of the brain injury. A series of structured questions were administered to the mothers of the head injured to elicit information regarding the current neurophysical and cognitive status of their son. The questions covered altered gait, visual defects, hearing defects, loss of the sense of smell, difficulty with verbal expression or comprehension, memory problems, independence in activities of daily living, and mobility outside the home. For each of these areas the mother could indicate whether a disorder was present or not. By combining these items an overall index of functional disability was established for each head injured subject.

\section{Emotional and social adjustment of the mother} a) The Leeds Scales of Depression and Anxiety. ${ }^{15}$ These self-report scales were used to assess the emotional status of the mother. They incorporate 15 items that describe common symptoms of anxiety and depression. In the general scales used in the study the possible range of scores is $0-18$ and the recommended cut-off score to suggest dysfunction is $6 / 7$ on each scale.

b) Self report social adjustment scale ( $S A S$ $M) .{ }^{16}$ This scale assessed social functioning of the mother in six role areas (work; social and leisure; relationships with extended family; relationship with spouse; functioning as a parent; and functioning in the family unit). The SAS-M is based on 45 questions, each rated on 
Table 3 Factor loadings on items of the current behaviour scale

\begin{tabular}{|c|c|c|c|}
\hline \multicolumn{2}{|c|}{ Factor 1: Loss of Emotional Control } & \multicolumn{2}{|c|}{ Factor 2: Loss of Motivation } \\
\hline Item & Item loading & Item & Item loading \\
\hline $\begin{array}{l}\text { Short tempered } \\
\text { Anxious, jumpy } \\
\text { Quarrelsome } \\
\text { Irritable } \\
\text { Verbally aggressive } \\
\text { Emotionally unstable } \\
\text { Restless } \\
\text { Self-centred } \\
\text { Depressed, low } \\
\text { Physically aggressive } \\
\text { Lacks self control } \\
\text { Impulsive }\end{array}$ & $\begin{array}{l}0.80 \\
0 \cdot 75 \\
0 \cdot 74 \\
0 \cdot 72 \\
0 \cdot 66 \\
0.68 \\
0.63 \\
0.62 \\
0.60 \\
0.58 \\
0.51 \\
0.40\end{array}$ & $\begin{array}{l}\text { Tired, fatigued } \\
\text { Drowsy, non alert } \\
\text { Lacks initiative } \\
\text { Lacks energy } \\
\text { Poor memory } \\
\text { Lacks spontaneity } \\
\text { Disinterested } \\
\text { Socially inappropriate } \\
\text { Talkative } \\
\text { Affectionate }\end{array}$ & $\begin{array}{l}0 \cdot 72 \\
0 \cdot 67 \\
0 \cdot 67 \\
0 \cdot 66 \\
0 \cdot 65 \\
0 \cdot 64 \\
0 \cdot 61 \\
0 \cdot 47 \\
0 \cdot 72 \\
0 \cdot 47\end{array}$ \\
\hline
\end{tabular}

a five point rating scale where a score of five indicates poor adjustment. A mean adjustment score can be derived for each role area and overall adjustment. The mother completed this scale in relation to her own social adjustment.

\section{Results}

Analysis of the current behaviour scale

The first objective in the data analysis was to determine whether the scale adequately represented the clinical variables: loss of emotional control and loss of motivation.

Using data only from the head injured group an unconstrained Principal Components Analysis produced eight factors with eigenvalues greater than unity. The first two factors accounted for $43 \%$ of the variance, whilst none of the other factors individually accounted for more than $10 \%$ of the variance. It was therefore decided to proceed with a Varimax (Orthogonal) rotation restricted to a two factor solution. From inspection of the items loading greater than 0.4 on each factor the two factors were considered to capture the essence of the more frequently reported behavioural change following severe closed head injury. The first factor (Factor A) was labelled as a Loss of Emotional Control factor and accounted for $27 \%$ of the total variance. The second factor (Factor B) was identified as a Loss of Motivation factor, accounting for $16 \%$ of the total variance (table 3 ).

To determine whether these factors from the behavioural scale could adequately discriminate between the head injured and control groups a stepwise Discriminant Function Analysis was undertaken. A single function was established consisting of both factors $A$ and $B$. This function could correctly classify $69 \%$ of grouped cases (table 4).

Descriptive profile of the functional disability of the head injured and the emotional adjustment of the mother

The head injured were reported to experience a range of neurophysical and cognitive deficits. Fifty five per cent were reported to have memory problems; $43 \%$ had expressive language problems; $30 \%$ had impaired gait; $25 \%$ had difficulty in vision. In contrast $15 \%$ had difficulty with language comprehension; $13 \%$ had a problem in the sense of smell; and $8 \%$ had difficulty with hearing. Ninety three per cent were independent or needed minimal assistance in routine activities of daily living; and $83 \%$ did not need any physical assistance outside the home.

Twenty three per cent of the mothers of the head injured in contrast with $5 \%$ of the control mothers were rated as depressed on the Leeds Scale $\left(\chi^{2}=5 \cdot 16, p<0.02\right)$. Anxiety levels from the Leeds Scale were similar for both groups (Mothers of head injured $20 \%$, control mothers $18 \%$ ). The overall social adjustment scale indicated that both groups of mothers were generally well adjusted in their various social roles (table 5). There was no significant difference between the groups on this global rating. Further analysis of the various specific role functions indicated that the mothers of the head injured were performing as well as the control mothers.

\section{Variables influencing reporting of behaviour}

The second stage of the analysis was to determine which of the selected variables could predict the mothers' reporting of behaviour following head injury.

Data were again only taken for the head injured group. Two separate stepwise multiple regression analyses were performed using Factor A and B from the Current Behaviour Scale as the dependent variables. The independent variables were chosen to represent head injury variables (Length of Coma, Time since injury, and the composite measure of Functional Disability) and the emotional status of the mother as measured by the Leeds Depression Scale. This measure was chosen since it was the only variable of emotional status that clearly discriminated between the groups. Thus in each regression there were four predictor variables. The simple correlations between these variables are presented in table 6 .

Using a stepwise multiple regression Leeds Depression entered the equation to predict Factor $A \quad\left(R^{2}=0 \cdot 16 ; \quad F(1,38)=7 \cdot 23\right.$, $\mathrm{p}=0.01$ ). It was also noted that by returning to the simple correlations of each variable with Factor $A$ the three measures of emotional status of the mother all show strong positive correlations with Factor $\mathrm{A}$ whereas the brain damage variables did not.

In contrast, the emotional status of the mother did not enter the regression equation to predict Factor B but the Functional Disability of the head injured did $\left(R^{2}=0.47 ; F(1\right.$, $38)=33.95, p=0.0000$ ). Thus as the functional disability of the head injured became greater the mothers were more likely to report their sons as apathetic or lacking in motivation. Chronicity of the injury bore no relationship to factor A or B.

Table 4 Classification results of the discriminant function analysis

\begin{tabular}{lll}
\hline & \multicolumn{2}{l}{ Predicted group membership } \\
\cline { 2 - 3 } Actual group & 1 Controls & 2 Head injured \\
\hline 1 Controls $(\mathrm{n}=40)$ & $30(75 \%)$ & $10(25 \%)$ \\
2 Head injured $(\mathrm{n}=40)$ & $15(37 \%)$ & $25(63 \%)$ \\
\hline
\end{tabular}


Table 5 Mothers' emotional status and social adjustment

\begin{tabular}{lll}
\hline & $\begin{array}{l}\text { Mothers of head injured }(n=40) \\
\text { Number of cases }\end{array}$ & $\begin{array}{l}\text { Control mothers }(n=40) \\
\text { Number of cases }\end{array}$ \\
Leeds depression & 9 & 2 \\
Leeds anxiety & 8 & 7 \\
& Mean $(S D)$ & Mean $(S D)$ \\
\hline Social Adjustment & & \\
Overall & $1.9(0.50)$ & $2 \cdot 0(0.37)$ \\
Work & $1.6(0.76)$ & $1 \cdot 8(0.59)$ \\
Social and Leisure & $2 \cdot 1(0.78)$ & $2 \cdot 0(0.53)$ \\
Extended family & $2 \cdot 1(0.65)$ & $2 \cdot 2(0.49)$ \\
Marital & $2.0(0.49)$ & $2 \cdot 4(0.49)$ \\
Parental & $1.6(0.69)$ & $1.7(0.69)$ \\
Family Unit & $1.7(0.67)$ & $1.7(0.73)$ \\
\hline
\end{tabular}

Table 6 Correlations between behavioural factors, brain injury variables and emotional status of the mothers

\begin{tabular}{lllllll}
\hline & Depression & $\begin{array}{l}\text { Leeds } \\
\text { Anxiety }\end{array}$ & $S A S-M$ & $\begin{array}{l}\text { Length of } \\
\text { coma }\end{array}$ & $\begin{array}{l}\text { Functional } \\
\text { disability }\end{array}$ & $\begin{array}{l}\text { Chronicity } \\
\text { of trauma }\end{array}$ \\
\hline Factor A & 0.40 & 0.42 & 0.44 & -0.17 & 0.14 & $-\begin{array}{r}0.26 \\
\text { Factor B }\end{array}$ \\
\hline
\end{tabular}

\section{Discussion}

The results of this study are consistent with clinical impressions that there are distinct quantifiable clusters of behaviours frequently observed after severe head injury and these can be grouped as loss of emotional control behaviours and loss of motivation, or lowered arousal behaviours. Head injured males were frequently reported by their mothers as impulsive, short tempered, emotionally unstable, restless, quarrelsome, self-centred and lacking in initiative and energy.

The behavioural factors identified within the Current Behaviour scale were able to achieve discrimination between head injured and control groups. Considering the chronicity of the head injured group ( $72 \%$ were interviewed five16 years after trauma) it is perhaps surprising that the factors achieved their current level of discrimination; the enduring quality of the behavioural features following head injury is emphasised and this was supported by the lack of correlation between chronicity and the mothers' reporting of behaviour. The perceived behavioural features after head injury would appear to be persistent, chronic features of this population. Whether any aspect of these behavioural features pre-dates the head injury remains to be addressed. Our impressions from the interviews with the mothers suggested that inter-personal relationships have substantially changed following the accident and most commonly these changes have been experienced as negative changes and closely related to behavioural, or personality changes. Further studies incorporating pre-accident estimates of behavioural profiles of subjects will develop our understanding of the nature of behaviour patterns related to head injury.

In relation to the broad assessment of social adjustment of the mothers the group data from both sets of mothers suggested good levels of functioning. Livingston et al ${ }^{17}$ suggested social maladjustment of relatives in the first posttrauma year but was unable to use control data to confirm this impression. The dysfunction was reported to be most evident in the area of marital functioning. In this study of chronic maternal adjustment marital functioning as measured by the SAS-M was not impaired in relation to the control group and many women spoke of the perception that the trauma had drawn the marriage closer together over time. Clearly in this chronic phase post trauma the mothers had substantially accommodated to the intrusion of brain injury in their everyday activities. Some degree of caution must be taken to prevent over-interpretation of these relative levels of adjustment. The crosssectional design of the study imposes limitations on the data and a longitudinal, prospective study is needed to delineate the process over time of family re-organisation following trauma. The data presented in this study may over-emphasise the mother-son relationships that survived (in some form) over the years. Nevertheless, as a group the mothers of the head injured appeared to have taken up the threads of their normal everyday interactions and activities. However, the emotional status of the mothers of the head injured was clearly problematic. Many more of the head injured mothers reported clinical levels of depression although anxiety levels were equivalent between the two groups.

Livingston et $a l^{17}$ also used the Leeds Scales among other measures to determine emotional status of relatives. In their study, at 12 months post-trauma, $37 \%$ of relatives reported levels of anxiety likely to be of clinical significance and $26 \%$ reported clinically significant levels of depression. By integrating this information with the results of our study it would appear that feelings of sadness and sorrow often will emerge early post-trauma in the family members and will not resolve over time. There is some suggestion, however, that levels of anxiety which are reportedly high in the acute stages will decrease with time. Again, prospective longitudinal data is much needed in this area to clarify the patterns of emotional adjustment patterns of the family over time.

It was found that the mothers' level of emotional distress was closely related to their reports of loss of emotional control behaviours in their sons but not with their reports of loss of motivation behaviours. These latter behaviours were strongly predicted by the resultant functional disability (or functional severity) of the brain injury. As the functional disability of the brain injury increased the mothers' were more likely to report their sons as apathetic, or generally lacking in motivation. Brooks and McKinlay ${ }^{4}$ reported that as the severity of brain injury increased, as inferred by length of PTA, then there was an increasing likelihood of relatives reporting overall personality change in the head injured. They further observed that length of PTA, however, did not appear to predict the extent of the change on the individual personality items.

Our study used loss of consciousness as its primary index of severity of brain injury and similarly could not discern a strong relationship between injury and behavioural outcome. However, by estimating the functional severity of the brain injury, that is, using a composite 
index of functional disability, this study highlights that it is that specific group of behaviours characterised by decreased initiative, lowered arousal and increased fatigue (see Factor B table 4) that represents the behavioural manifestation of the severity of functional disability associated with generalised, diffuse blunt head injury. Elaboration of the relationship between specific foci of brain injury (for example, frontal lobe damage) and resultant behavioural profile will be problematic within the head injured population since the essence of such an injury is to create diffuse non-localising damage. Early comprehensive monitoring of the features of brain injury indicating the nature of the underlying pathophysiology may elicit interesting brain-behaviour relationships following brain trauma. This would also contribute to the clinical need for early prediction of psychosocial outcome. These behaviours are certainly difficult for the family to cope with but they do not promote the extreme family distress associated with the presence of emotional instability.

Loss of emotional control is characterised by disinhibition, impulsivity, frequent mood changes and irritability. These behaviours are the target of many reported behavioural programmes which appear to achieve some degree of behavioural control but require constant vigilance by the close relative to maintain appropriate behaviour. A prospective study is necessary to determine the complex development of the relationship between emotional distress of the mother and her reporting of emotional instability in the son but it would be a parsimonious explanation to suggest that the behaviour of the son promotes an increase in the mothers' emotional distress. It is understandable that a moody, unpredictable, explosive young male is difficult to live with in the family home and would easily provoke distress in those close family members around him. The disability of the son creates the handicap of the family.

The importance of isolating this group of behaviours as being particularly damaging in the long term to the emotional health of the family is that it refines the prediction of long term outcome following severe brain injury. Early monitoring of the head injured who display marked signs of loss of emotional control behaviours could serve to identify families at risk in long term outcome. Targetted programmes of intervention could then be prescribed.
Unfortunately, the study also highlights the specific interweaving of the disability of those that are head injured and the health of their close family. Rehabilitation and the long term care of the severely head injured necessitates a family focus and the needs of the family deserve greater recognition within rehabilitation programmes than is commonly available.

We would like to thank the subjects and their families for participation in the study, Caulfield and Hampton Rehabilitation Hospitals for permission to involve their patients, Lorraine Elsass for development of an original version of the behrioural cale, Simone Allan Innnaral scale, Simone Allan, Lynne Antcliffe, Samantha Burns, Gordana Joldeski, Louise Sellenger, Eric Tyssen, Elisa Villani and
Kathryn White who assisted in the collection of the control data.

1 Bond MR, Brooks DN. Understanding the process of recovery as a basis for the investigation of rehabilitation for the brain injured. Scand J Rehab Med 1976;8:127-33.

2 Weddell R, Oddy M, Jenkins D. Social Adjustment after rehabilitation: a two year follow-up of patients with severe head injury. Psychol Med 1980;10:257-63.

3 Oddy $M$, Coughlan $T$, Tyerman A, Jenkins D. Social adjustment after closed head injury: a further follow up seven years after injury. $J$ Neurol Neurosurg Psychiatry 1985;48:564-8.

4 Brooks DN, McKinlay W. Personality and behavioural change after severe blunt head injury - a relative's view. J Neurol Neurosurg Psychiatry 1983;46:336-44.

5 Prigatano G. Personality and Psychosocial consequences after brain injury. In: Meier MJ, Benton A, Diller L, eds. Neuropsychol Rehab. New York: Guildford Press, 1987.

6 Levin HS, High WM, Goethe KE, Sisson RA, Overall JE Rhoades HM, Eisenberg HM, Kalisky Z, Gary HE. The neurobehavioural rating scale: assessment of the behavioural sequelae of head injury by the clinician. $J$ Neurol Neurosurg Psychiatry 1987;50:183-93.

7 Lezak MD. Living with the characterologically altered brain injured patient. J Clin Psychiatry 1978;39(7):592-8.

8 McKinlay WW, Brooks DN, Bond MR, Martinage D, Marshall M. The short-term outcome of severe blunt head injury as reported by relatives of the head injured person. injury as reported by relatives of the head injured

9 Kinsella G, Ford B, Moran C. Survival of social relationships following head injury. Intern J Dis Studies 1989; 11:9-14.

10 Chetcutti B. Behavioural outcome in severely head injured males; a relationship with the mothers' psychological status. Unpublished Psychology Honours thesis, La Trobe University 1987.

11 McKinlay WW, Brooks DN. Methodological problems in assessing psychosocial recovery following severe head injury. J Clin Neuropsychol 1984;6(1):87-99.

12 Elsass L, Kinsella G. Development of a scale for measuring behaviour following closed head injury. 14th Annual Conference Australian Society for the Study of Brain Impairment, Melbourne, Australia 1989.

13 Elsass L, Kinsella G. Social interaction following severe closed head injury. Psycholog Med 1987;17:67-85.

14 Osgood CE, Suci GJ, Tannenbaum PH. The measurement of meaning. Urbana: University of Illinois Press, 1957.

15 Snaith RP, Bridge GWK, Hamilton M. The Leeds Scales for the self-assessment of anxiety and depression. London: Psychological Test Publication, 1976.

16 Cooper P, Osborn M, Gath D, Feggetter G. Evaluation of a modified self-report measure of social adjustment. $\mathrm{Br} J$ Psychiatry 1982;141:68-75.

17 Livingston MG, Brooks DN, Bond MR. Patient outcome in the year following severe head injury and relatives psychiatric and social functioning. I Neurol Neurosurg Psychiatry 1985;48:876-81. 